\title{
Chromatographic party in Valencia (ISC 2010)
}

\author{
Yolanda Pico • Joan O. Grimalt
}

Published online: 31 March 2011

(C) Springer-Verlag 2011

From 12 September to 16 September 2010, the International Symposium on Chromatography (ISC) celebrated its 28th event in Valencia (Spain). This event was organized by the Spanish Association of Chromatography and Related Techniques (SECyTA) and returned to Spain 36 years after the tenth symposium had been celebrated in Barcelona in 1974. The present symposium was attended by 570 registered participants. About 500 communications were given, 122 of them in oral form within four parallel sessions. In addition, there was a commercial exhibition involving 22 companies. Many of these gave vendor sessions providing information on their latest technical developments in chromatography.

Numerous interesting lectures were given by invited speakers such as Georges Guiochon and Lois Ann Beaver from the University of Tennessee, Knoxville (USA), Ian D. Wilson from AstraZeneca, Macclesfield (UK), Boguslaw Buszewski from Nicolaus Copernicus University, Toruń (Poland), Alejandro Cifuentes from the

Published in the special issue Advances in Analytical Separations with Guest Editors Yolanda Pico and Joan O. Grimalt.

\section{Y. Pico $(\square)$}

Food and Environmental Safety Research Group,

Department of Medicine Preventive, Faculty of Pharmacy,

University of Valencia,

Av. Vicent Andrés Estellés s/n,

46100 Burjassot, Valencia, Spain

e-mail: yolanda.pico@uv.es

\section{J. O. Grimalt}

Department of Environmental Chemistry,

Institute of Environmental Assessment and

Water Research (IDÆA-CSIC),

Jordi Girona 18,

08034 Barcelona, Spain

e-mail: joan.grimalt@idaea.csic.es
Institute of Industrial Fermentations (IFI-CSIC), Madrid (Spain), Salvatore Fanali from the Institute of Chemical Methodologies (CNR) Monterotondo Scalo (Rome, Italy), Vaclav Kasicka from the Institute of Organic Chemistry and Biochemistry, Prague (Czech Republic), Ryszard Lobinski from the University of Pau and Pays de l'Adour, Pau (France), Amadeo R. Fernandez-Alba from the University of Almería, Almería (Spain) and Jean-Luc Veuthey from the University of LausanneUniversity of Geneva (Switzerland).

Several awards were given at the symposium. The Tswet \& Nernst Prize on Science for Life given by the European Society for Separation Sciences (EuSSS) to two distinguished scientists was given to Guenther Bonn from the Institut für Analytische Chemie und Radiochemie, University of Innsbruck (Austria), and Vadim A. Davankov from the Nesmeyanov Institute of Elemental Organic Compounds, Russian Academy of Sciences, Moscow (Russia). The EuSSS Award to a scientist under 35 years old who has made leading contributions to chromatography and related techniques was given to María Ibáñez Martínez from University Jaume I, Castellón de la Plana (Spain). In addition, SECyTA gave the José Antonio García Domínguez Award for the best oral communication to M. Nocun and J.T. Andersson from the Institute of Inorganic and Analytical Chemistry, University of Münster (Germany).

Poster awards were also given, such as the José Antonio García Domínguez Award for the best poster to E.B. Pashkova, A.V. Pirogov and O.A. Shpigun from Moscow State University, Moscow (Russia), and for the second best poster to $\mathrm{O}$. Hernández-Hernández, R. Lebrón, J. Quintanilla-López, M.L. Sanz and F.J. Moreno from the Spanish Council for Scientific Research (CSIC), Madrid (Spain). Analytical and Bioanalytical Chemistry (Springer) was also present, and three Springer poster awards were given to S. Wiese, T. Teutenberg, M.A. Jochmann, D.M. 
Kujawinski, L. Zhang, B. Fischer and H. Bettermann from the Institute of Energy and Environmental Technology from the University of Duisburg-Essen (Germany), J. Chamieh, C. Faye, O. Vandenabeele-Trambouze, T. Moreau, K. Faure, V. Dugas, C. Demesmay and J. Randon from the universities of Lyon and Montpellier II (France) and E. Alechaga, E. Moyano and M.T. Galceran from the University of Barcelona (Spain).

This special issue entitled Advances in Analytical Separations is a collection of full papers based on some of the presentations given at the 28th ISC covering different aspects of separation science, including the development of new stationary and liquid phases or chromatographic systems for separation and characterization of complex mixtures. However, the greater part is devoted to applications to industrial, environmental and food samples, covering a broad range of analytes (e.g. pharmaceuticals and veterinary drugs, pesticides, ochratoxin A, perfluorinated compounds, soy isoflavones, mannosylerythritol lipid surfactants and carotenoids), matrices (e.g. milk, eggs, wine, juices, oils and refined products, surfactants, water, sewage sludge, soil and sediments) and separation approaches (e.g. surfactant-mediated mobile phases, extraction sorbents based on aptamers, ionic liquid as a stationary phase, capillary monolithic titania columns and liquid exchange chromatography). The symposium placed special emphasis on chromatographic applications for the analysis of food and feed products and this is reflected in the present issue because several of the instrumental and analytical improvements were used for the analysis of these materials. However, the area of separation science is an exciting and rapidly moving field, and we look forward to many new analytical advances in the coming years.

We would like to thank sincerely all the authors for their time and effort in preparing their contributions and the editorial staff of Analytical and Bioanalytical Chemistry for their invaluable assistance during the preparation of this special issue. We hope that the readers of Analytical and Bioanalytical Chemistry will enjoy reading these contribu- tions and trust they will help to broaden the horizons for developments in this field.

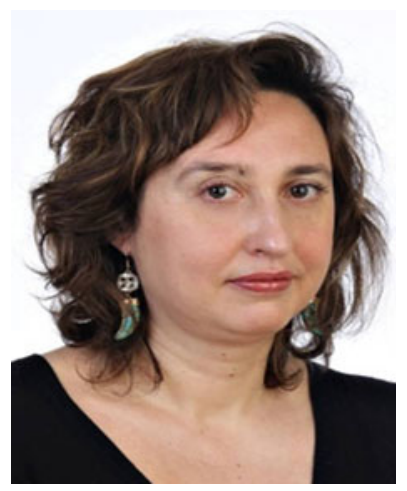

Yolanda Pico has been a full professor of nutrition and food science at the University of Valencia since 1998. Her research interests include identification of unknown compounds by liquid chromatography-mass spectrometry, microextraction separations and environmental and food safety. She is the author of nearly 180 peerreviewed papers, 140 scientific papers in journals and 25 book chapters and is the editor of three books on food and environmental safety and applications of liquid chromatography-mass spectrometry. Presently, she is Vice-president of the Spanish Society of Chromatography and Related Techniques (SECyTA).

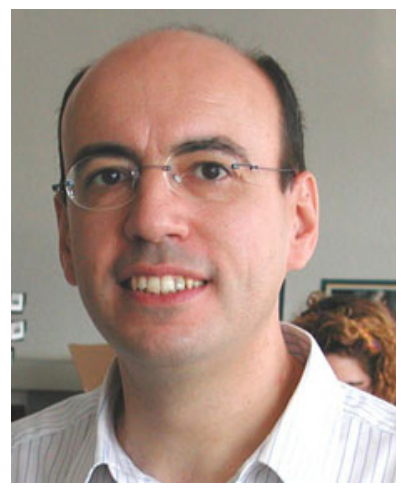

Joan O. Grimalt is a research professor at and the director of the Institute of Environmental Assessment and Water Research (IDÆA) of the Spanish Council for Scientific Research (CSIC). His professional activity is within environmental organic geochemistry. More specifically, his research is devoted to the study of natural and anthropogenic organic compounds as markers of the health status of ecosystems and living organisms (including humans). To date he has published about 520 scientific papers, most of them in international peer-reviewed journals. Presently, he is President of the Spanish Society of Chromatography and Related Techniques. He received the King Jaume I award devoted to the preservation of the environment (Valencian Autonomous Government, 2005), the Environment Award of the Catalan Academia (2001) and the Award of Scientific Research of the City of Barcelona (2000). 